\title{
Editorial
}

\section{Em meio à pandemia}

\author{
Marcelo Lopes de Souza \\ Luciano Zanetti Pessôa Candiotto
}

A pandemia de COVID-19 entrará para os anais da história mundial, ao lado dos atentados de 11 de setembro de 2001, como um dos episódios mais marcantes, traumáticos e cheios de consequências do primeiro quartel do século XXI. A rigor, é bem provável que o conjunto dos efeitos dessa pandemia venha a ser mais significativo que os do atentado às Torres Gêmeas, por envolver efeitos e mudanças que vão muito além da segurança pública e do controle social.

No que se refere aos fatores, a pandemia permanecerá sendo, durante décadas, um exemplo a ser estudado a propósito de questões como o papel do autoritarismo (não só chinês, pelo escamoteamento de informações no início da pandemia), do oportunismo político e da manipulação de informações pelo Estado (o Brasil, juntamente com os Estados Unidos, seguramente serão sempre lembrados a respeito disso tudo). No que tange aos desdobramentos, é certo que ela será estudada como um momento decisivo não apenas com relação à história das crises econômicas - no momento em que este editorial é escrito, é patente que seremos confrontados, globalmente, com graves problemas econômicos, talvez chegando a uma recessão sem precedentes -, mas também no que se refere às estratégias de controle e disciplinamento dos cidadãos e seus corpos pelo aparelho de Estado capitalista, bem como a uma tendência de intensificação de atividades e relações sociais no âmbito do ciberespaço (decorrente do 
uso da Internet e de redes sociais). Quanto a tudo isso, aliás, a dimensão política dos discursos científicos e técnicos certamente não deixará de estar sob escrutínio crítico. Isso tudo sem mencionar o fato de que essa pandemia com certeza não será a última: enquanto houve duas pandemias ao longo de todo o século XX (Gripe Espanhola e AIDS), só nestas décadas iniciais do século XXI já tivemos outras três - a SARS (2002-2003), a do vírus H1N1 (2009-2010) e, agora, a da COVID-19. A frequência, em parte como decorrência da própria globalização e da continuidade de um processo planetário de mudança climática e degradação ambiental, está aumentando. Seja lá como for, uma coisa é certa: a vida será uma antes e outra depois dessa calamidade epidemiológica, sanitária e econômico-social. O capitalismo saberá (aliás, já está sabendo) se aproveitar das chances de lucro proporcionadas, direta ou indiretamente, pela catástrofe em curso. Entre os assalariados, em contrapartida, decerto haverá muito mais perdedores que ganhadores, mormente se pensarmos nos trabalhadores pobres.

Os artigos que compõem o presente número de AMBIENTES não fazem menção ao novo coronavírus ou à pandemia da COVID-19. Também, pudera: não se tratando de escritos de circunstância ou análises de conjuntura, elaborados no calor dos acontecimentos e de curto fôlego, mas sim de trabalhos que refletem anos de pesquisa e reflexão, e que já estavam preparados ou bastante adiantados quando a pandemia nos tragou a todos em seu torvelinho, dificilmente seria possível acomodar a temática da tragédia à lógica de produção dos trabalhos concretos. Não obstante isso, e olhando para o futuro, uma coisa salta aos olhos: poucas coisas são tão geográficas quanto essa pandemia, tanto em suas causas quanto em suas consequências, especialmente do ponto de vista da Geografia Ambiental (e, interdisciplinarmente, da Ecologia Política). Senão, vejamos: o aparecimento e a difusão do novo coronavírus, culminando com a pandemia, são, em si mesmos, exemplos extraordinários de fenômenos socionaturais "híbridos", a mesclar processos e dinâmicas tanto sociais (hábitos culturais, relações de poder e interesses econômicos) quanto naturogênicos (para começar, o próprio vírus SARS-CoV2, que é seu nome técnico, é, ao que parece, fruto de seleção natural). Acima de tudo, a 
tragédia da pandemia é, nitidamente, um problema ecossocial, que combina condições geoecológicas específicas (e variáveis de país para país e de região para região) com interferências humanas deliberadas as mais diversas (igualmente variáveis segundo o país e a região, a despeito das notáveis semelhanças comportamentais e, sobretudo, políticas), oferecendo vasto material para estudos geoambientais em sentido amplo, nos quais os aspectos sociogeográficos e ecogeográficos sejam conjugados.

Diante disso, é lícito afirmar que a Geografia com certeza irá, doravante, oferecer contribuições científicas de peso para a análise da COVID-19, assim como de futuras epidemias e pandemias - não é mesmo? Infelizmente, nosso otimismo tem de ser, quanto a isso, bastante moderado, na melhor das hipóteses. Apesar de a Geografia da Saúde ser uma vertente em ascensão (mas que deita raízes na antiga "Geografia Médica"), e a despeito do óbvio interesse da análise geográfica para as pesquisas epidemiológicas (e vice-versa), os geógrafos que se ocupam dessas questões ainda constituem um nicho muito reduzido, e nada sugere que o panorama deve mudar radicalmente, pelo menos no curto prazo. Talvez haja, sim, um maior interesse dos geógrafos, inclusive por causa da ampla e profunda repercussão social (maior, sem dúvida, que a de epidemias e pandemias anteriores, com exceção da famigerada Gripe Espanhola de 1918-1920). Não obstante, é de se perguntar: estaria a Geografia bem preparada, epistemologicamente falando, para enfrentar o desafio de oferecer contribuições de peso ao esforço analítico de esquadrinhar fenômenos como a pandemia da COVID-19? E estaria ela bem equipada, teórico-conceitual e metodologicamente, para estar à altura de uma tal tarefa? Por fim: será que a consciência da relevância de uma colaboração desse tipo se acha já disseminada? É muito difícil, honestamente, responder um decidido "sim" a essas três perguntas, principalmente à última.

É bem verdade que, nos últimos meses, multiplicaram-se os artigos em periódicos assinados por geógrafos e dedicados ao tema da pandemia do coronavírus (sem contar as lives e mesas virtuais sobre o assunto). Não obstante, não nos enganemos: de longe, a maior parte do material até agora publicado parece constituir-se de textos de 
circunstância, mistura de reflexão com análise de conjuntura, e não de resultados de pesquisas propriamente. Por mais que esses escritos possam, muitas vezes, ser úteis ou esclarecedores, eles não substituem os resultados de um real esforço de estudo sistemático e de longo prazo. Neste momento, muita gente sente uma grande necessidade de se manifestar, seja a título de "desabafo", seja para acompanhar uma tendência de não silenciar sobre algo que a todos mobiliza; isso é válido e compreensível. No entanto, percebe-se, também a propósito dessa temática, a mesma dinâmica de “acompanhar uma moda", tantas vezes já vista no passado, que termina, não raro, por dar ensejo à proliferação de produtos banais, superficiais e repetitivos. Análises de conjuntura e reflexões gerais, mesmo quando inteligentes e bem informadas (ou seja, daquele tipo que bem poderia ser feito por bons jornalistas e ensaístas), não eximem os geógrafos de protagonizarem pesquisas consistentes.

Muito embora, no plano epistemológico, a Geografia tenha sempre sido vista (se bem que, a partir dos anos 1970, não tanto pelos próprios geógrafos) como um campo potencialmente fertilíssimo, justamente, para análises integradas do "metabolismo social" e dos vários vínculos (materiais e discursivos) entre "sociedade" e "natureza" justamente o tipo de análise requerido para o estudo aprofundado de fenômenos como as pandemias e seus efeitos sócio-espaciais -, sabemos que essa identidade, na prática, se enfraqueceu nas últimas décadas. Em decorrência disso, as ferramentas teóricoconceituais e metodológicas, apesar de se terem sofisticado enormemente, em geral foram desenvolvidas ou aprimoradas de maneira fragmentada, e muito pouco foram testadas no contexto de pesquisas integradas, no estilo advogado pela Geografia Ambiental. Por isso, toda prudência é pouca: não é evidente ou seguro que os geógrafos saberão ou terão condições de aproveitar as possibilidades que a história da disciplina aponta, e para as quais essa história, com todos os seus percalços, não deixa de poder servir como inspiração.

É claro, porém, que o tom não precisa ser de pessimismo. Afinal de contas, a própria movimentação que tem resultado no projeto de uma Geografia Ambiental indica 
que a toalha não foi jogada sobre o ringue. Principalmente, cumpre insistir, pensando sobretudo nas novas gerações de geógrafos, sobre as extraordinárias possibilidades que surgem, no que diz respeito à Geografia Ambiental, em matéria de interlocução com a Epidemiologia (em especial com a Epidemiologia Ambiental), sem mencionar o diálogo com a "Geografia da Saúde", a Ecotoxicologia e áreas correlatas ou afins, dentro e fora dos limites da própria Geografia.

Para a Geografia Ambiental, beneficiando-se de seu espírito científico integrador mas, também, de sua vocação (muito inspirada, quanto a isso, na experiência e na tradição da Ecologia Política) para o diálogo de saberes para além da academia, surge, com esse tipo de interface, uma oportunidade como poucas para demonstrar sua utilidade e sua importância perante a sociedade como um todo. Um dos veios a serem explorados nesses marcos é, aliás, o tema/desafio da justiça ambiental, que é objeto de preocupações de um dos artigos deste número. Outro pode estar na identificação e análise de diversas iniciativas populares de organização e cooperação, que têm sido construídas na luta pela sobrevivência em face da pandemia, sobretudo em locais onde o Estado, historicamente, mais atrapalha e oprime do que ajuda, como em favelas, comunidades indígenas, comunidades ribeirinhas etc. Existe, muitas vezes, um potencial enorme por trás de tais experiências, em matéria de ganhos de autonomia/redução da heteronomia e avanços em direção a processos de autogestão.

Com o intuito de contribuir para uma agenda de pesquisa e diálogo, uma questão central pode orientar a reflexão dos geógrafos a respeito da atual conjuntura e seus desdobramentos: o que a pandemia de COVID-19 nos mostra, no que se refere ao conteúdo emancipatório ou não das iniciativas tomadas e interpretações assumidas por diversos agentes sociais (associações de moradores e outras organizações da sociedade civil, órgãos do aparelho de Estado, imprensa etc.), e quais as implicações espaciais/ambientais dessas iniciativas e interpretações? Partindo dessa questão, surgem várias outras indagações. 
Com o isolamento forçado, o tempo das pessoas no ciberespaço tem aumentado substancialmente. O ciberespaço já é uma realidade há muito tempo (ao menos a partir da década de 1990), e tem atingido, além de crianças e jovens, pessoas de todas as idades. Sabendo dessa intensificação do tempo social no ciberespaço, e de mudanças que virão após o período de isolamento, não estaríamos rumando a um distanciamento cada vez maior do espaço concreto (onde há uma constante interação entre processos naturogênicos e sociais)? Aqui, é preciso levar em consideração que o ciberespaço é, de alguma forma, uma extensão do espaço material e, portanto, do ambiente, proporcionado pelo avanço técnico. Parece, porém, estar havendo uma tendência de que o tempo vivenciado em nossas residências, em frente de uma tela de computador, tablet ou celular, substitua, perigosamente, o tempo vivenciado nas ruas, nas praças e nos parques, no contato direto com outras pessoas. Não estaremos correndo o risco, ao lado de fenômenos como a autossegregação das elites e classes médias em bolhas de segurança ("condomínios exclusivos"), de vermos a experiência do contato social e da vivência do ambiente (em sentido amplo) ser cada vez mais empobrecida? Quais as possíveis consequências sociopolíticas (ou, quem, sabe, também em matéria de saúde psíquica) da substituição dos ambientes reais, com a sua complexidade, os seus desafios e as suas contradições, por ambientes virtuais, que funcionam como nichos e circuitos em que, em geral, convive-se entre iguais? Não nos arriscamos a ter uma visão cada vez mais distorcida e simplificada sobre o espaço geográfico e sua produção?

Seja como for, a percepção de que todos vivemos em um único planeta (a chamada "sociedade global”), interconectado apesar das desigualdades, foi aguçada com a pandemia. Um problema que se tornou comum à humanidade pode contribuir para uma maior solidariedade entre as pessoas - mas, também, para que o individualismo, o elitismo e os sectarismos sejam aguçados. Recentes declarações de governantes demonstram que o egoísmo, a xenofobia, o ódio, o oportunismo e a ganância podem ser grotescamente "justificados", com o argumento de que é preciso evitar outras pandemias e catástrofes. No plano social, o discurso de "quebra da economia" e "defesa 
de empregos" deverá ser amplamente instrumentalizado para promover perdas de direitos (relacionados ao trabalho, à mobilidade e à privacidade, entre outros). A dimensão espacial de tudo isso é patente, seja sob a forma de novas ou renovadas restrições de mobilidade, interdições de acesso, acentuação de segregação e estigmatização sócio-espacial e, por último, mas não com menor ênfase, agravamento de quadros de injustiça ambiental, em que a vulnerabilidade dos trabalhadores pobres quando de novas epidemias/pandemias será repetidamente escancarada.

Resta-nos, assim, torcer para que, daqui para a frente, em particular em face de novas epidemias e pandemias - e tudo indica que o próprio aquecimento global está a criar as condições para que tragédias dessa natureza se repitam várias vezes, nos anos vindouros -, os geógrafos sejam, cada vez mais, também profissionais ouvidos e respeitados pelo que têm a dizer acerca de assuntos tão profundamente... geográficos.

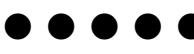

No momento em que AMBIENTES: Revista de Geografia e Ecologia Política chega a seu segundo ano de existência, o Número 1 do Volume 2 traz oito artigos - com contribuições de cunho teórico-metodológico e empírico - e uma resenha. Os temas, problemas e ideias aqui abordados são extremamente úteis na atualidade, seja ao resgatar elementos históricos que nos permitem melhor entender as dinâmicas ambientais de nossos dias (onde o social está, necessariamente, implicado, de várias formas e com variáveis intensidades), seja no tratamento de eventos e de lutas que envolvem problemas ambientais contemporâneos, como a relação entre contaminação ou desastres e segregação residencial (e, mais amplamente, desigualdades sócioespaciais), o rompimento de barragens, a apropriação de territórios a partir da criação de unidades de conservação, a circulação transfronteiriça de resíduos sólidos e a remoção de favelas. 
Em uma tentativa de propor caminhos para consolidar o esforço de construção do enfoque da Geografia Ambiental no Brasil e na América Latina, particularmente de um ponto de vista socialmente crítico, Marcelo Lopes de Souza explora, no artigo intitulado "Articulando ambiente, território e lugar: A luta por justiça ambiental e suas lições para a epistemologia e a teoria geográficas", a necessidade de articularmos aqueles três conceitos tão caros à Geografia, a fim de podermos melhor captar a complexidade das lutas por justiça ambiental ao redor do mundo. Em meio a reflexões de fundo de natureza conceitual (a propósito dos referidos três conceitos, bem como do conceito de justiça ambiental), histórica (a respeito de alguns aspectos da evolução do pensamento geográfico), teórica e epistemológica, o autor oferece breves análises de três exemplos de situações de injustiça ambiental. Estas são compreendidas e construídas enquanto “objetos epistêmicos híbridos", ilustrando como o estudo da problemática da injustiça ambiental e a reflexão sobre os conflitos e ativismos em torno disso podem colaborar decisivamente para evidenciar a importância do olhar integrador que é próprio da Geografia Ambiental.

O sociólogo argentino, professor e pesquisador da Universidade Nacional de Catamarca, Horacio Machado Araoz, possuidor de uma trajetória em pesquisas sobre mineração no âmbito da Ecologia Política, é o autor de "La minería colonial y las raíces del Capitaloceno: Habitus extractivista y mineralización de la condición humana". Após resgatar as "raízes minerais do capitalismo" e suas nefastas consequências ambientais, através da conquista europeia da América Ibérica, iniciada com Cristóvão Colombo, o artigo destaca a revolução da mineração em Potosí, Bolívia, como um marco na mineração comercial, bem como na origem da Modernidade Ocidental. A influência da mineração na subjetividade e na institucionalidade, bem como na alteração do processo "geosociometabólico" entre o ser humano e a natureza não humana, levando ao que denomina "mineralização da condição humana", também é discutida. Tal alteração, segundo o autor, foi o fator determinante para o surgimento do "Capitaloceno", que alguns autores vêm propondo como alternativa crítica ao "Antropoceno". 
Seguindo com a temática da mineração, mas abordando as tragédias ocorridas em Mariana e Brumadinho/MG, o geógrafo alemão e professor da Universidade Federal de Minas Gerais (UFMG), Klemens Augustinus Laschefski, evidencia diversos problemas da mineração e das ações pós-rompimento das barragens empreendidas pela Samarco Mineração S.A., dentre os quais se destacam os seguintes: o processo de licenciamento ambiental e a subserviência dos órgãos ambientais; a gestão ineficiente de reparação de danos; a flexibilização de normas; e, por fim, a ampliação do controle territorial das áreas afetadas pelos desastres por meio de "grilagem oculta de terras" (hidden landgrabbing). As informações apresentadas no artigo "Rompimento de barragens em Mariana $e$ Brumadinho (MG): Desastres como meio de acumulação por despossessão" fundamentam o argumento do autor acerca de um tipo de "terrorismo" da empresa para com os moradores e afetados por esses eventos, potencializando o sofrimento das pessoas e as consequências ambientais oriundas do rompimento das duas barragens de rejeitos minerais.

O historiador ambiental Arthur Soffiati, protagonista de uma admirável atuação intelectual e ativista ambiental de longa data na área da Baixada Campista (RJ), realizando também provocações políticas e filosóficas sobre a "questão ambiental" desde a década de 1980 (Soffiati foi, aliás, o entrevistado de AMBIENTES em seu primeiro número), é autor do artigo “Breve história da globalização ocidental e seus custos ambientais". Permeando os períodos Paleolítico e Neolítico e chegando até a Civilização Ocidental, onde aborda o modo de produção capitalista, desde a Revolução Industrial até a contemporaneidade, Soffiati oferece uma interpretação eco-histórica da globalização como um processo multifacetado e de longo prazo. Nesse contexto, ele aponta elementos da crise ambiental atual, decorrente da racionalidade ocidental, que, ideologicamente, separou o ser humano da natureza, ao conceber esta enquanto mero objeto e mercadoria.

Com o auxílio do conceito de "urbanidades florestais", os geógrafos Diogo Cabral, Alexandro Solórzano e Rogério de Oliveira, demonstram, a partir do exemplo das 
florestas urbanas na cidade do Rio de Janeiro, especificamente aquelas dos maciços da Tijuca e da Pedra Branca, como se deu a regeneração florestal nessas áreas, após a exploração e supressão de grande parte de suas florestas nativas. No artigo "Florestas Urbanas e Urbanidades Florestais no Rio de Janeiro - Uma Geografia Histórica", o predomínio da espécie exótica jaqueira em alguns trechos e a existência de pequenos platôs esculpidos na encosta são apresentados como evidências de uma sucessão ecológica ocorrida após o desmatamento florestal e de uma paisagem cultural com rugosidades quilombolas, "escondida" na floresta. Os autores deixam patente a complexidade da história dos vínculos entre sociedade e natureza nas florestas urbanas estudadas.

O artigo escrito por Brenda Ponzi, geógrafa e doutoranda na Universidade Nacional do Centro da Província de Buenos Aires, identifica agentes e projetos que influenciam na criação e gestão do Parque Nacional Patagonia, localizado na Província de Santa Cruz, Argentina. Com base nos conceitos de territorialização e territorialidades, Brenda Ponzi enfatiza o que denomina territorialidades conservacionistas, vinculadas a estratégias de instituições públicas e privadas no tocante à apropriação e administração do referido Parque, bem como de outras áreas protegidas no país. No artigo “Han tomado la parte del fondo: La territorialización del Parque Nacional Patagonia, Santa Cruz (Argentina)", além dos projetos conservacionistas, também são examinados os projetos agropecuários e mineiros, fundamentais na ocupação e produção do espaço geográfico na região, bem como na negação de territorialidades pré-existentes.

A partir da assinatura, por parte de 187 países, da Convenção de Basiléia, instituída em 1989, que dispõe sobre o Controle de Movimentos Transfronteiriços de Resíduos Perigosos e seu Depósito, Luciana Ziglio discute alguns eventos de movimentação de resíduos de origens diversas, provenientes de outros países para o Brasil, incluindo questionamentos sobre o recente problema relacionado ao derramamento de óleo na costa brasileira, em 2019, com origem inconclusiva até o momento. Assim, o artigo "Comércio internacional de resíduos sólidos urbanos e a Convenção de Basileia: 
Contribuições para a poluição por óleo no litoral brasileiro" discute os tipos de resíduos incorporados na referida Convenção e os problemas do tráfico ilícito de resíduos estrangeiros para o Brasil.

O artigo de Tiago Boruchovitch Fonseca é uma contribuição geográfica relacionada à necessidade de relativizarmos criticamente e encararmos com cautela os discursos e medidas de "proteção ambiental". Partindo de um resgate histórico a respeito da política de remoção de favelas no município do Rio de Janeiro/RJ, o artigo “Políticas de remoção: Velhas práticas, novas justificativas. O caso das favelas localizadas no Bairro do Alto da Boa Vista - Rio de Janeiro e a instrumentalização conservadora da questão ambiental", aborda elementos de uma ecogeopolítica urbana, com base nas contribuições teórico-conceituais a esse respeito de Marcelo Lopes de Souza. Para ilustrar esse debate, Tiago Fonseca examina a pressão para a remoção de mais de dez favelas no bairro do Alto da Boa Vista (situadas na zona de amortecimento do Parque Nacional da Tijuca, que também se acha abordado, de uma diferente perspectiva, no artigo de Diogo Cabral, Alexandro Solórzano e Rogério de Oliveira), na cidade do Rio de Janeiro, que tem tido lugar nas duas últimas décadas.

Por fim, Luciano Zanetti Pessôa Candiotto comenta, na forma de resenha, a obra Ambientes e territórios: Uma introdução à Ecologia Política, de autoria de Marcelo Lopes de Souza, publicada em 2019 pela editora Bertrand Brasil, do Rio de Janeiro. Consciente tanto da importância da Ecologia Política para os geógrafos (em especial, claro, para aqueles que praticam a Geografia Ambiental) quanto da lacuna existente em língua portuguesa a propósito desse importantíssimo campo interdisciplinar, Marcelo Lopes de Souza oferece, com a obra Ambientes e territórios, uma útil e urgente discussão de assuntos como justiça ambiental, conflitos ambientais e vários outros - entre os quais se inclui uma densa articulação dos conceitos de território e ambiente (e também de lugar). 